\title{
The Case for an Independent Fiscal Institution in Japan
}




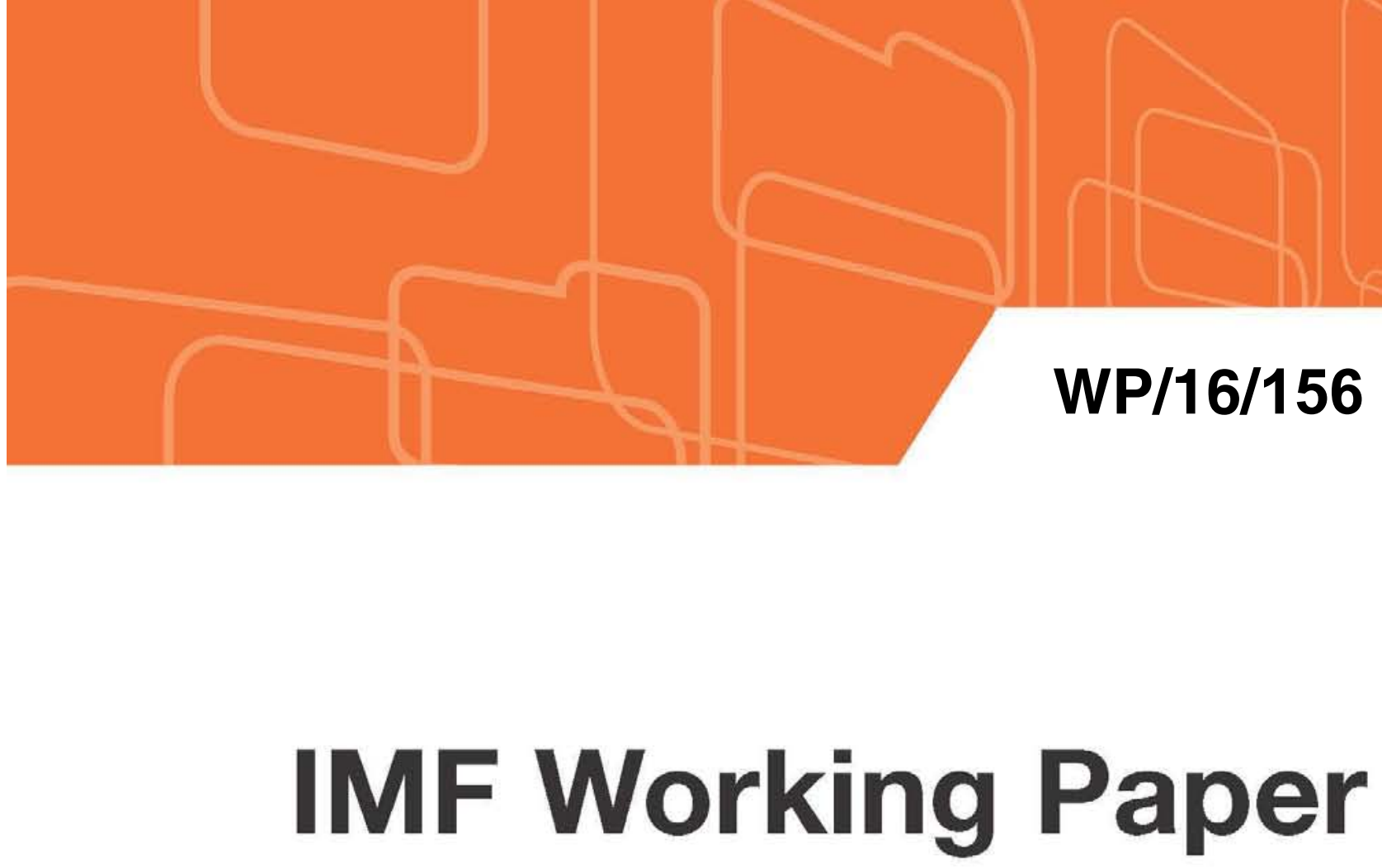

\section{The Case for an Independent Fiscal Institution in Japan}

by George Kopits

IMF Working Papers describe research in progress by the author(s) and are published to elicit comments and to encourage debate. The views expressed in IMF Working Papers are those of the author(s) and do not necessarily represent the views of the IMF, its Executive Board, or IMF management.

I N TER N A T I O N A L MONETARY FUND 


\title{
IMF Working Paper
}

Asia and Pacific Department

\section{The Case for an Independent Fiscal Institution in Japan}

Prepared by George Kopits ${ }^{1}$

Authorized for distribution by Luc Everaert

August 2016

IMF Working Papers describe research in progress by the author(s) and are published to elicit comments and to encourage debate. The views expressed in IMF Working Papers are those of the author(s) and do not necessarily represent the views of the IMF, its Executive Board, or IMF management.

\begin{abstract}
In response to the recent financial crisis and the ensuing buildup in public indebtedness, an increasing number of advanced economies have created independent fiscal institutions (IFIs) to improve the quality of public finances and to strengthen the credibility of government policy. A review of Japan's fiscal policymaking over the past decades suggests that Japan would greatly benefit from establishing an IFI in line with internationally accepted standards of good practice. Such an institution could help correct critical weaknesses in policymaking and anchor expectations, especially if introduced as part of a fiscal framework with a medium-term perspective.

JEL Classification Numbers: E61, E62, H11, H63.

Keywords: Japan's fiscal policy; public debt sustainability; independent fiscal institutions.

Author's E-Mail Address: George.Kopits@wilsoncenter.org

\footnotetext{
${ }^{1}$ The author is a senior scholar at the Woodrow Wilson Center and member of the Portuguese Public Finance Council. This paper was prepared while he was an IMF visiting scholar. A preliminary version was presented at an ADBI Distinguished Speaker Seminar, in Tokyo, December 11, 2015. Comments by T. Kitamura, H. Tanaka, H. Ueno, M. Ueno, N. Yoshino and other seminar participants are gratefully acknowledged. The paper has benefited from useful inputs from E. Arbatli, Luc Everaert, and I. Saito.
} 
I. What Are Independent Fiscal Institutions? What is Their Origin? Are They Effective?....... $\underline{3}$

A. Definition, Basic Mandate .......................................................................

B. Origins, Rationale....................................................................................

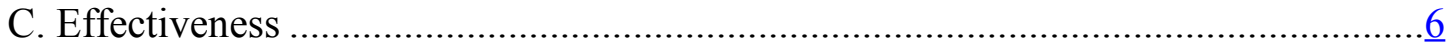

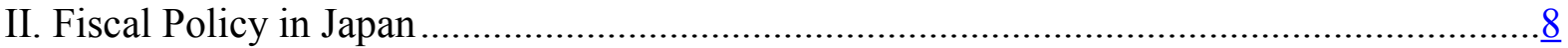

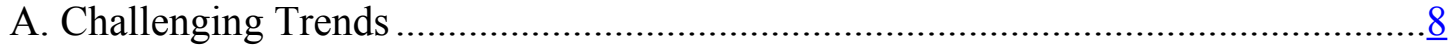

B. Fitful Policymaking ..............................................................................

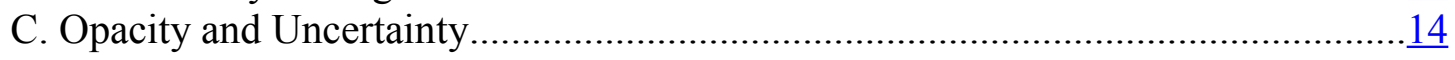

III. International Overview ................................................................................ 15

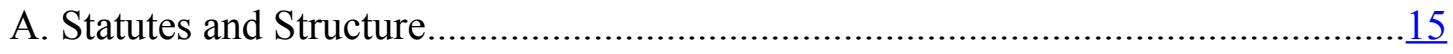

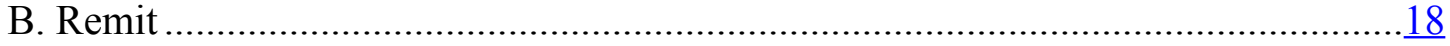

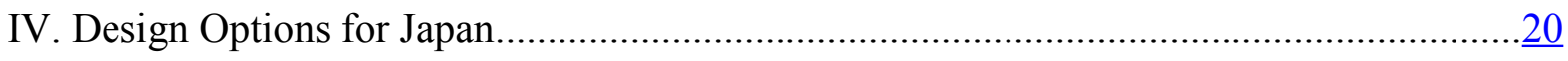

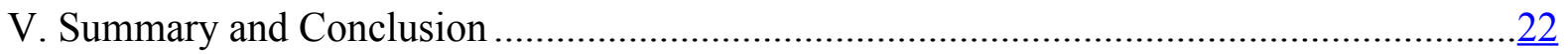

Tables

1. Advanced Economies: Statutes and Structure of Independent Fiscal Institutions............... 16

2. Advanced Economies: Functions of Independent Fiscal Institutions ..............................18

Figures

1. General Government Balance and Output Gap, 2000-15 …........................................ 9

2. Selected Advanced Economies: Average Forecast Errors for General Government Balance,

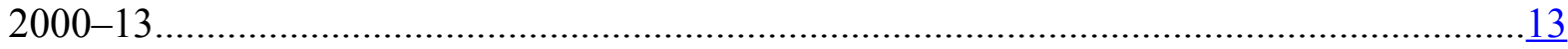

3. Selected Advanced Economies: Average Forecast Errors for General Government Debt,

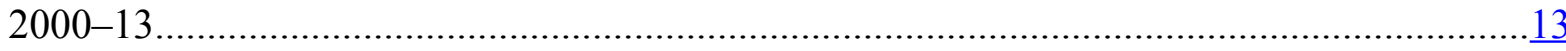

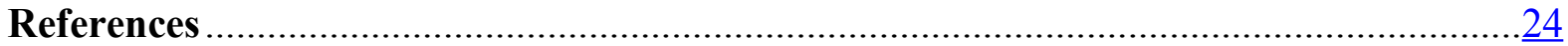


In recent years, a new generation of independent fiscal institutions (IFIs) has proliferated in advanced economies, as well as in some emerging market economies, partly in response to the financial crisis and the ensuing buildup in public indebtedness, unprecedented in peacetime history. In general terms, the rationale for IFIs stems from the quest for transparency in public finances, and thereby, for improving fiscal policymaking.

The purpose of this paper is to examine the case for establishing an IFI for Japan, given past trends, current conditions, and future outlook. To this end, the rationale, experience and effectiveness of existing IFIs are reviewed, to assess their potential relevance for Japan. In addition, drawing on international good practice, the paper explores the features of such an institution which would be most suitable to address Japan's public finances.

The paper organized as follows. Section I outlines the distinguishing features, rationale, and effectiveness of IFIs. Section II highlights major trends and characteristics of Japan's fiscal policy over the past two decades. Section III provides a panoramic overview of IFIs in advanced economies, distilling lessons of relevance for Japan. Section IV suggests design options for consideration in establishing an IFI in Japan. Section V concludes.

\section{What ARE INDEPENDENT Fiscal InSTITUTIONS? WhAT IS ThEIR ORIGIN? ARE They EFFECTIVE?}

\section{A. Definition, Basic Mandate}

In general, IFIs are entrusted with vigilance over public finances mainly by evaluating fiscal policy usually before and during the decision-making process. They are charged with realtime forward-looking surveillance of fiscal policymaking, with focus on macro-fiscal effects in the short to medium run, and on public debt sustainability over the long run. The principal role of the institution - known under various names such as fiscal council or parliamentary budget office - is analysis and assessment of the budget bill or of any other legislative proposals in the fiscal area, prior to enactment. In some countries, the mandate extends beyond the central government, to the rest of the public sector, namely, decentralized agencies, subnational governments, and public enterprises.

The IFI differs from other independent institutions that may have monitoring responsibilities too. In particular, they differ significantly from public audit institutions that have been operating in most countries around the world - some of them for over a hundred years. Although equally independent, the audit institution is responsible for conducting a detailed ex post inspection of the physical, financial and legal integrity of every public sector entity; in some countries, this task is complemented with performance audits. Thus, whereas the audit office discharges an indispensable backward-looking evaluation, the IFI has a forwardlooking diagnostic task. While the former is comprised of a large number of lawyers, auditors and accountants, latter is generally staffed with just a small group of mostly economists. 
In some countries, as an integral part of a rules-based fiscal framework, the IFI is also responsible for evaluating the consistency of the budget bill, or of the medium-term budgetary plan, with fiscal rules or targets. But the IFI is regarded as beneficial in a discretionary policy environment as well; the first fully operational IFIs were established to monitor discretionary fiscal policy (Belgium, Netherlands, US).

In fulfilling its mandate, the IFI must be de facto independent from all branches of government, including in terms of work program and control over its human and financial resources. This does not preclude formal attachment to the legislative, the executive, or the judicial branch, ${ }^{2}$ or the fact it is subject to standard audit, as any other public entity. It serves primarily the legislature and the public at large; they are its principal clients. In this capacity, it must be non-partisan, so that its opinions are shaped by technical analysis alone. This precludes bi-partisanship, whereby it would attempt to balance views of various political or regional interest groups.

Although the surveillance function carried out by the independent fiscal institution conceivably can be entrusted to another independent institution, in practice such an arrangement has not met with success. In fact, an attempt to assign this responsibility to the national audit office (UK) has failed, given the lack of expertise to carry out real-time economic analysis. Similarly, entrusting the oversight function to an independent central bank (Peru) has not been satisfactory because of differences in policy focus, as well as the bank's inhibition to make a critical analysis of government policy, risking its independence from the government. In addition, surveillance of fiscal policy by a supranational authority (European Union) through peer review has failed to overcome the culture of mutual tolerance of breaches of fiscal rules among member governments - a deeply ingrained characteristic until the advent of the debt crisis. In a recent innovation, a fiscal council has been grafted, along with its functions (with an appropriate technical staff), onto the existing court of audit (France); the success of this novelty will depend on the effective degree of separation between the ex ante and ex post oversight under the same institutional roof. ${ }^{3}$

In any case, the IFI has no policy-making authority, and by implication, it cannot have legally binding enforcement power. Unlike monetary policy, fiscal policy by its very nature cannot be outsourced for two reasons. First, whereas monetary policy is assigned primarily the price stability goal, fiscal policy serves multiple objectives: stabilization, allocative, and distributional goals. Second, a democratically elected government cannot entrust fiscal policy

\footnotetext{
2 The system of government can determine the institution's independence. While in a Westminster-style parliamentary system the institution should be independent from both the executive and the legislature, in a presidential system it is usually sufficient if the institution is independent from the executive.

${ }^{3}$ A negative feature is the potential conflict of interest between the two tasks in that the same institution evaluates the budget bill that audits it. On the other hand, the IFI can benefit from the well-established reputation of impartiality of the Cour des Comptes in France.
} 
to an unelected independent authority, absent a well-defined principal-agent relationship between the government and the fiscal institution. ${ }^{4}$

Good practice for IFIs, along these characteristics, has been codified in the Principles for IFIs by an OECD reference group, consisting of heads of these institutions, and recommended formally to member countries, including Japan, by the OECD Council. In all, these 22 internationally accepted principles are grouped under nine broad headings: local ownership; independence and non-partisanship; relationship with the legislature; access to information; transparency; communication; and external evaluation. ${ }^{5}$

\section{B. Origins, Rationale}

The heterogeneity of IFIs is determined above all by the circumstances prevailing at their origin and the rationale of their adoption across different countries. According to origin, IFIs can be classified as the result of local political conditions; prompted by fear of, recovery from, a crisis; or owing to an external commitment by the government. A number of IFIs emerged due to a confrontation between political parties, where in some cases a major opposition party extracted the adoption of an IFI as a concession from the government (e.g., United States). More recently, the IFI was established by the government in the aftermath of a crisis to recuperate some erosion in credibility toward citizens and financial markets (e.g., United Kingdom), or simply as a requirement under a Fund-supported stabilization program (e.g., Ireland) or under EU membership (most EU members). Adoption of the IFI came about with varying degrees of consensus from local stakeholders, which determined to an extent the success of the institution.

The rationale underlying the creation of the IFI varied over a wide range of arguments. The foremost argument has been the need for transparency in public finances, as the key to informed and quality policymaking. More specifically, through comprehensive and timely access to information on the government's policy intentions and execution, the IFI is intended to correct three interrelated deficiencies in fiscal management in advanced and emerging market economies. If successful in mitigating or correcting these weaknesses, IFI can help anchor fiscal expectations, much like an independent central bank can help anchor inflation expectations. ${ }^{6}$

The first deficiency is the deficit bias and the associated procyclicality bias in fiscal policy that can be observed not only in many emerging market economies, but also in advanced economies, notably in Europe, especially during economic upswings. In some cases,

\footnotetext{
${ }^{4}$ For a comparison of the delegation of authority in the fiscal and monetary areas in the UK, see Wren Lewis (2013).

${ }^{5}$ See OECD (2013).

${ }^{6}$ See the analysis underlying this point in Leeper (2010).
} 
procyclicality is reinforced by within-year supplementary budgets. Japan's high debt and remaining high deficits would suggest that such biases may be a feature of its budgeting process.

Second, the optimistic bias in macro-fiscal projections is an inherent practice of many governments - characterized as fiscal illusion in a classical tract of political economy. ${ }^{7}$ This bias may arise not only from optimistic underlying macroeconomic assumptions (output and interest rate), but also, albeit less frequently, from optimistic effective tax elasticities or takeup rates for social entitlements. ${ }^{8}$ In addition, the optimistic bias frequently reflects dynamic inconsistency in the government's commitment to a medium-term fiscal consolidation.

Third, following the financial crisis, an increasing number of highly indebted governments have been facing a fiscal sustainability problem. Over time, the problem becomes increasingly severe as governments fail to address with medium- and long-term projections predicated on realistic underlying productivity and demographic assumptions, while taking into account risks associated with contingent liabilities. In the event, they are likely to postpone a much-needed adjustment.

\section{Effectiveness}

Assessing the effectiveness of an IFI is rather complex. Ideally, effectiveness can be defined in terms of impact on fiscal performance, measured by an indicator of changes in the budget balance relative to a counterfactual outcome in the absence of the IFI that cannot be observed. More realistically, it might be assessed through the impact on some aspect of policymaking, such as the transparency in public finances. A related potential measure of impact is on public perceptions, as revealed in surveys or press coverage, or on market perceptions as reflected in levels and changes in sovereign risk premiums and ratings. While such broad approaches at measuring effectiveness may be informative, none of them are immune to measurement limitations and none can be regarded as reliable. By the same token, quantification on the basis of a cross-country sample of highly heterogeneous IFIs is subject to limitations. ${ }^{9}$

At a practical level, the central question on effectiveness involves the influence of the IFI on specific policy settings or policy decisions. This influence can take place directly or indirectly. Even with the most established IFI seldom has direct influence on policymaking that is observable in an episode where the government or the legislature changes policy course, modifies a budget bill, or retracts a proposed measure when confronted by an adverse

\footnotetext{
${ }^{7}$ Puviani (1907) observed and documented the tendency of governments to overestimate the benefits and underestimate the budgetary costs of any proposed expenditure program or tax relief measure.

${ }^{8}$ See the empirical analysis based on wide country coverage in Frankel (2011).

${ }^{9}$ See Debrun and Kumar (2007), IMF (2013) and Beetsma and Debrun (2016) on estimates of the effectiveness of IFIs on fiscal performance with cross-country data.
} 
IFI opinion. Far more frequent, though perhaps less tangible, is the indirect influence exercised through the legislative debate, policy dialogue in think tanks, or public reaction to IFI views reported in the media.

Most powerful indirect influence takes place in a preemptive manner, through the technical arm of the executive or legislature, which alerts the political decision-makers as to the potential critical IFI assessment that would elicit a given policy measure under consideration. Such indirect influence eludes statistical documentation and can only be supported with anecdotal evidence, yet it intensifies over time as the role of the IFI becomes routine and anticipated by the press and the public. ${ }^{10}$

Any evaluation of the effectiveness of IFIs is clouded by the above considerations. More generally, the institution may be simply a formal manifestation of the government's political commitment, underpinned by the electorate's preference for discipline. And as noted, it is difficult to ascertain the influence of the IFI, through more subtle means, as fiscal behaviour over time may be conditioned by the mere presence of the institution - whereby the government anticipates, and therefore averts, a potential confrontation with the institution.

Although in most countries the track record of IFIs is rather short, all have had a positive impact on fiscal transparency, while their effect on fiscal performance has been mixed-as evidenced in a number of case studies. ${ }^{11}$ To quote Sir Alan Budd (2013), the first chair of the UK Office for Budget Responsibility, IFIs "can be a powerful force for good." And as observed by Alice Rivlin (2013), the founder of the US Congressional Budget Office, IFIs "can play an important role in ensuring realistic and well-informed debate based on honest numbers, focusing attention on the consequences of action (or inaction), and identifying more or less sustainable solutions to budget dilemmas. They cannot instill political courage to make unpopular decisions. Political leaders have to do that for themselves."

For an IFI to be successful it has to meet certain basic conditions. Besides adhering to the good practices spelled out in the OECD Principles, the IFI must be home-grown and homeowned, developed on the basis of the broadest possible consensus; it must be endowed with adequate financial and human resources, with proven competence to perform quantitative analysis; and it must possess communication skills to gain the support of the media and the general public. Moreover, to earn credibility, it is essential for the IFI to demonstrate nonpartisanship and technical competence at the initial phase of operation. But, even after a successful start, upon having met all the foregoing conditions, IFIs are rather fragile institutions that are exposed to the will of elected officials and require an extended tenure

\footnotetext{
${ }^{10}$ See for example the description of the experience of the US Congressional Budget Office by Joyce (2011).

${ }^{11}$ See detailed country studies in Kopits (2013a).
} 
before being well established. ${ }^{12}$ To claim success, an IFI needs to operate at least over two electoral cycles, with major political parties alternating each other in government. ${ }^{13}$ Ultimately, the success of the institution depends on public's demand for transparency and accountability from elected political leaders, and its refusal to regard public finances as a black box.

\section{Fiscal Policy in Japan}

This section is an attempt at identifying key features in Japan's fiscal behavior that may bolster or refute arguments for setting up an IFI. Well-known policy dilemmas faced by the authorities and the policies adopted in coping with those dilemmas, as well as major future challenges, are brought under scrutiny to assess the case for an IFI in Japan.

\section{A. Challenging Trends}

Over more than two decades, Japanese policymakers have struggled to emerge from the prolonged stagnation that followed the financial crisis of the early 1990s. Periodic attempts at stimulating the economy through monetary and fiscal policies did not yield a much-hoped sustained revival. In fact, apart from brief rebounds, the specter of a recessionary spiral reappeared, along with the risk of deflation, aggravated by the effects of two major external shocks, the global financial crisis and a natural disaster.

In this context, fiscal policy occupied a prominent role by injecting several rounds of "revitalization." The fiscal expansion - to a large extent consisting of public investment often in public works projects with limited return - contributed to a sharp rise in public indebtedness. Lackluster economic performance prevailed well into the early 2000s, the continued attempt at maintaining an expansionary fiscal stance notwithstanding. Conversely, despite the significant withdrawal of stimulus from 2003 until the onset the crisis, the output gap remained close to zero (Figure 1). Nonetheless, the fiscal impulse and countercyclical stance adopted since the crisis may have helped alleviate the effects of the financial crisis in 2008-09 and the Fukushima disaster in 2011, though at the cost of a further buildup in the public debt ratio. On balance, there is no evidence to corroborate that the policy stance over the last decade or so has been significantly procyclical-unlike in several advanced

\footnotetext{
12 The very existence of an IFI is under threat by a government that cannot tolerate critical assessments by independent institutions. The first institution to succumb was Venezuela's Congressional Budget Office, following three years of operation, terminated by President Hugo Chávez in 2000. Similarly, after two years of successful operation, Hungary's former Fiscal Council lost all funding, its remit was significantly narrowed and its technical staff abolished under Prime Minister Viktor Orbán at the end of 2010.

13 The US Congressional Budget Office earned a reputation for impartiality well into the Carter administration, following the Nixon and Ford administrations, only after it was able to display the same critical demeanour toward both governments.
} 
economies where governments adopted an expansionary fiscal stance during the Great Moderation.

The apparent inefficacy of fiscal policy and the accompanying public indebtedness, since the 1990s, gave rise to a lively debate in academic circles and among policy analysts both inside Japan and abroad, much of it supported by careful research. ${ }^{14}$ On one side of the debate, some scholars explained this development with the Ricardian argument that Japanese households and enterprises may have stepped up their savings during the fiscal expansion in anticipation of future fiscal retrenchment. Since Japan was approaching a liquidity trap at the zero-lower-bound interest rate, it was necessary instead to give an added boost to monetary expansion. On the other side, adherents to the Keynesian view advocated further fiscal expansion; when confronted with the apparent inefficacy of fiscal tools, they cited the counterfactual case, arguing that absent a fiscal stimulus the economy would have sunk into depression, and regarded the low fiscal multipliers as a transient phenomenon. As well, there was no evidence of crowding out, evidenced by low prevailing interest rates, largely attributable to monetary accommodation.

Figure 1. Japan: General Government Balance and Output Gap, 2000-15 (In percent of potential GDP)

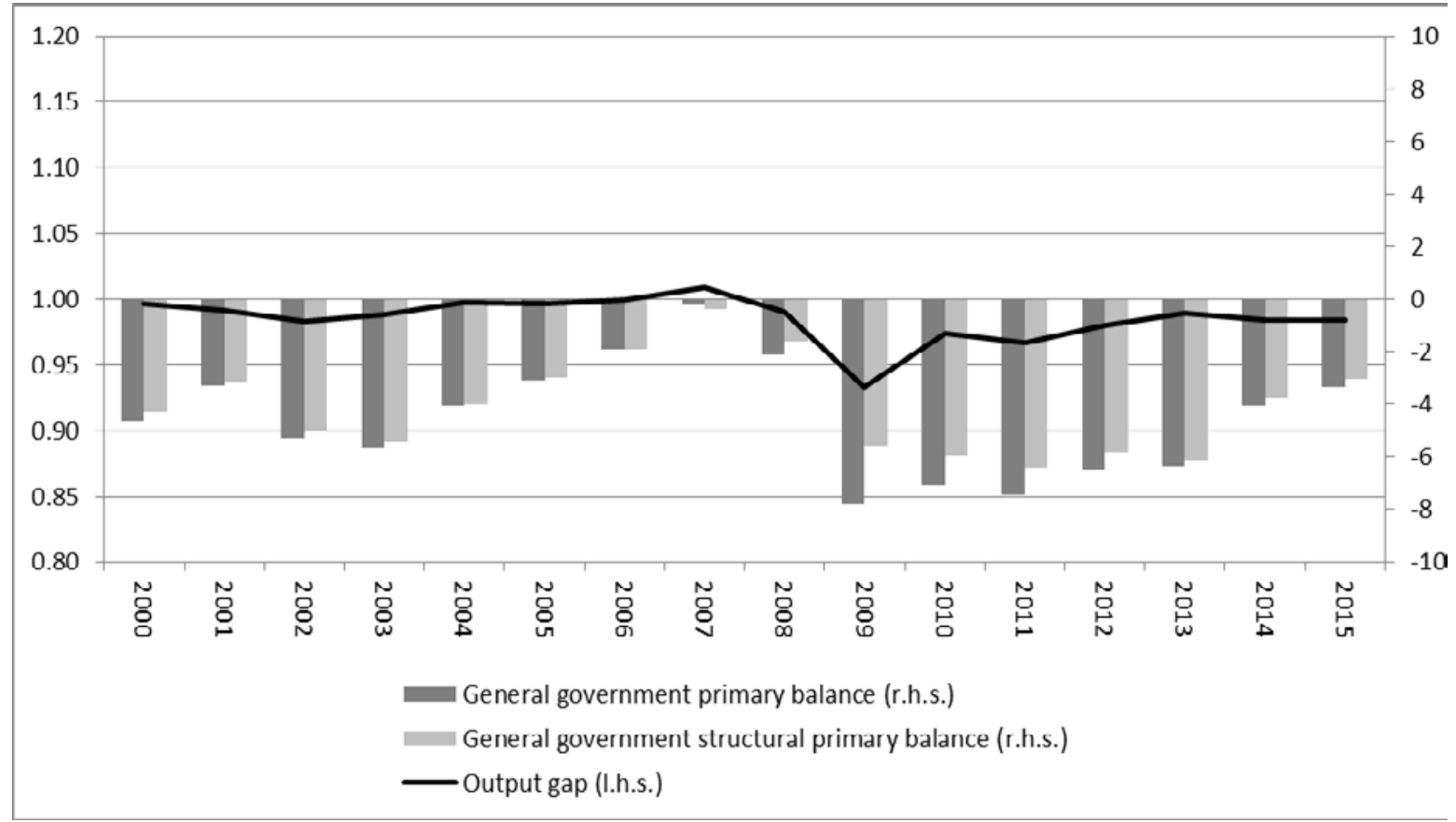

Source: IMF, World Economic Outlook

${ }^{14}$ See, for example, contributions to the debate by Krugman (1998), Walker (2002), and Werner (2004). 
Likewise, there were divergent views about the rise in the public debt ratio. Whereas some felt that this could be corrected over time with acceleration in growth, partly through structural reforms, others expressed concern about an irreversible fiscal sustainability problem. In any event, the home bias ${ }^{15}$ of Japanese households and financial institutions in holding domestic sovereign bonds - despite the very low interest yield even in real termswas expected to continue protecting the country from the threat of a sudden stop in financing from abroad due to shifts in investor sentiment, as in episodes of capital account crises.

\section{B. Fitful Policymaking}

The debate in the context of conventional macro-fiscal analysis, while informative, has been largely inconclusive. Instead, a more promising approach consists of examining political economy aspects of policymaking and its likely impact on fiscal expectations. This involves the interactions within the government, the role of the Diet, the influence of vested interests, as well as public perceptions of the government's intentions over a medium-term horizon.

Since the early 1990s, formulation of fiscal policy in Japan has straddled an unenviable dilemma between boosting economic activity on the one hand and preserving debt sustainability on the other. ${ }^{16}$ The dilemma, since the recent crisis, is no longer unique to Japan, as a number of advanced economies, especially in Europe, are confronted with the choice between macro stabilization and debt sustainability, against the backdrop of declining potential growth and low equilibrium real interest rates. Admittedly, the dilemma cannot be solved with the ongoing unprecedented monetary expansion alone. There must be some recourse to fiscal policy, but above all, to structural reforms. In Japan, the tradeoff between stabilization and sustainability seems much sharper than elsewhere and is likely to intensify, short of a regime shift.

Typically, the process of budgetary preparation, legislation, and execution takes place on the basis of a well-established choreography. The Ministry of Finance (MoF) interacts with the Cabinet Office of the Prime Minister (CO) in a top-down iterative process of setting the envelope and allocation of primary expenditures for spending ministries and agencies, on the basis of macroeconomic forecasts prepared by the $\mathrm{CO}$ and revenue forecasts by the MoF. Each summer, the MoF initiates this process by formulating soft expenditure ceilings for the next fiscal year for each line ministry - which the latter is encouraged to observe within a margin of up to 10 percent - as an increment over budgeted spending in the preceding year. This process occurs in consultation with the $\mathrm{CO}$ which sets macro-fiscal goals for the forthcoming fiscal year and scenarios for the medium term.

\footnotetext{
${ }^{15}$ To be sure, the search for yield through carry-trade investments abroad, including short-term bank lending prior to the Asian crisis, did not dent the home bias.

${ }^{16}$ See Ihori (2014) for an analysis of the dilemma from a political economy perspective.
} 
The budgetary process is played out amidst an almost continuous tension between the MoF, staffed by adherents to fiscal discipline, and the $\mathrm{CO}$, which responds to immediate political pressures from the ruling party or coalition parties seeking to satisfy an overall demand for stimulus and specific demands for fiscal benefits from key interest groups. While the MoF is driven by an overarching concern for restoring debt sustainability, the $\mathrm{CO}$ aims at adopting an expansionary stance in dealing with a common pool problem. ${ }^{17}$

In the recent dynamics of the budgetary process, the MoF has tended to underestimate revenues - except during economic downturns - ${ }^{18}$ apparently to balance the optimistic underlying macroeconomic assumptions by the $\mathrm{CO}$. The optimistic bias is evident mainly in the medium-term projections, which are in fact scenarios rather than projections. This is especially true for the high-growth "revitalization" projection, which can be interpreted as the government's elusive goal-embodied in the government's medium-term fiscal plansand to a lesser extent for the "prudent" projection. As an upshot, optimistic growth assumptions leave fiscal policy without a credible medium-term anchor. Finally, altogether absent is a no-policy-change baseline projection against which to assess the estimated effect of the envisaged measures.

In the course of the fiscal year, as the revenue outcome is usually more favorable than forecast, the new information gives rise to additional demands that are met with added spending in a routine supplementary budget. During the past twenty years there have been more than 40 supplementary budgets, averaging about two per year, estimated to total 8 percent increase in primary expenditures over initial appropriations; the increase was 6 percent excluding 2008-09 and 2011. Although the public may expect a supplementary budget every year, this practice still creates unpredictability as the government may not respond to the prevailing cyclical condition or the size of the output gap in a systematic way. Furthermore, this prevents automatic stabilizers from being the first line of defense against procyclicality.

As a result of above pattern in the budgetary process, both forecast revenue and expenditure tend to be understated relative to outturn. But as the understatement of expenditure usually exceeded the understatement of revenue, the budget deficit was understated on average by 0.5 percent of GDP in the "prudent" projection and by nearly one full percentage point in

\footnotetext{
${ }^{17}$ This is a salient example of the tug of war between politicians and civil servants described by Tanaka (2014b) that was exposed during the DPJ administration. Increasingly, the politicians seem to have been gaining the upper hand under the current LDP administration. As reported by Harding (2016), [Prime Minister] "Abe has neutered the Ministry of Finance.... [He] no longer trusts the ministry or its projections, after it told him a 2014 consumption tax rise would have only a modest and transient effect on the economy. Instead, it caused a recession."

${ }^{18}$ Over the last 15 years, the revenue outturn exceeded forecast every year except during output decline in 200102 and 2007-09. The MoF has argued that the recent positive forecast errors reflect corporate tax revenue which were also underestimated by corporate taxpayers - the basis of MoF forecasts.
} 
third year in the "revitalization" projection, over the period 2000-13. The understatement of government debt was much larger, presumably reflecting stock-flow effects and difference in coverage: the forecast error rose from 3 percent in the first year to 9 percent in the "prudent" projection and to 11.5 percent in the "revitalization" projection.

The upshot of the current policymaking process is that the authorities' fiscal behavior is not only unpredictable, but also reflects considerable optimistic bias. In an international comparison of three-year forecast errors in 2000-13, Japan exhibits an optimistic bias that exceeds that of most other advanced European economies for both the government balance and debt (Figures 2 and 3$)^{19}$. The bias seems to be particularly pronounced in Japan's debt ratio, which surpasses the ratio of all other countries except Denmark. ${ }^{20}$ Although forecast errors during this period have been compounded by the Great Recession affecting all countries (with the exception of Sweden), this effect is reduced in the case of Japan by omitting the forecasts for 2009.

\footnotetext{
${ }^{19}$ The forecast errors for all countries are based on official government forecasts of fiscal and macroeconomic aggregates for the current and one and two years ahead.

${ }^{20}$ In Denmark, public debt declined steadily from over 70 percent of GDP in 1995 to 26 percent in 2007, and was projected to keep falling significantly in subsequent years. Instead, in the wake of the financial crisis, the adoption of a fiscal stimulus and recapitalization of some financial institutions, along with contracting activity, led to an unanticipated rise in the debt ratio to well over 40 percent in the following years, significantly larger than forecast.
} 
Figure 2. Selected Advanced Economies: Average Forecast Errors for General Government Balance, 2000-13

(In percent of GDP)

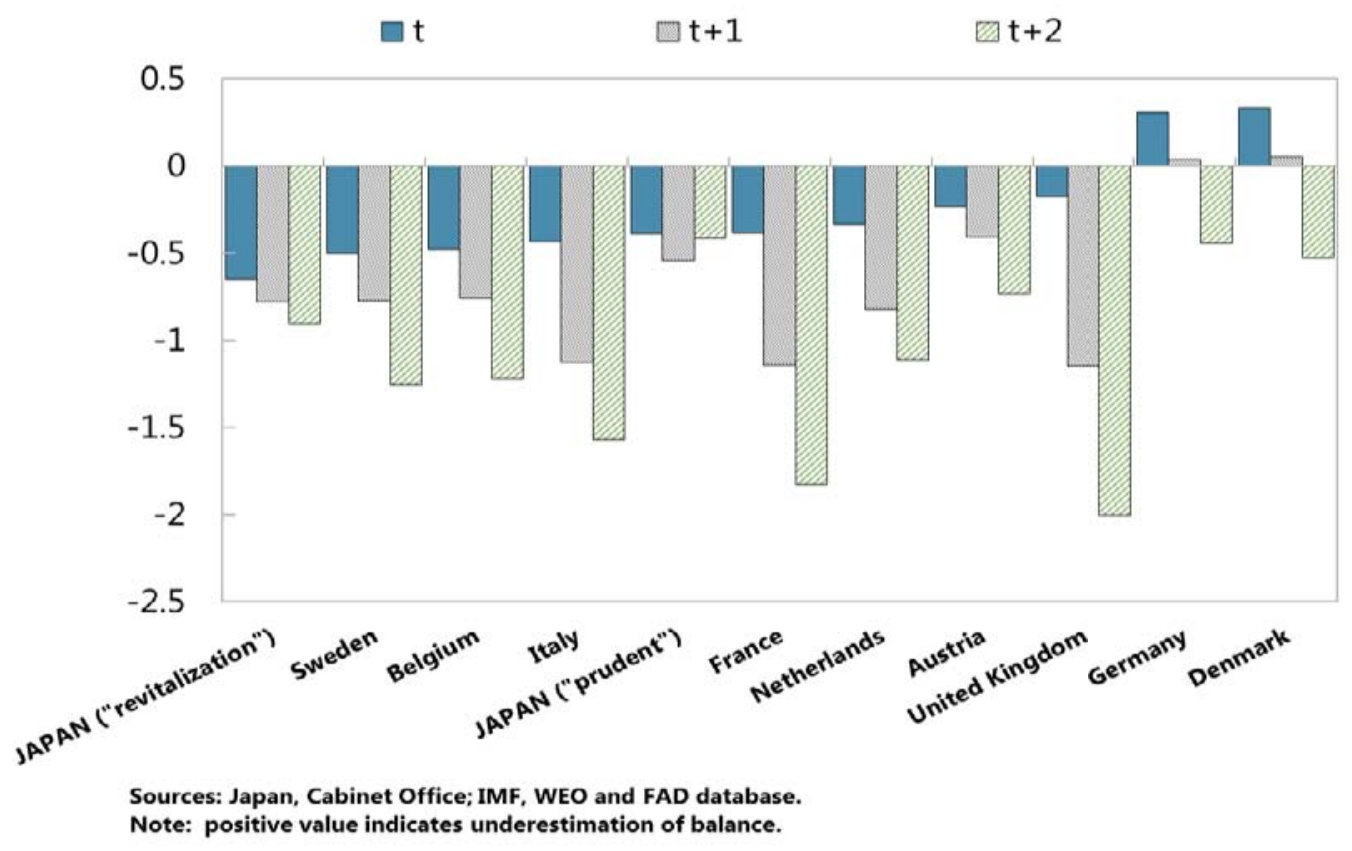

Figure 3. Selected Advanced Economies: Average Forecast Errors for General Government Debt, 2000-13

(In percent of GDP)

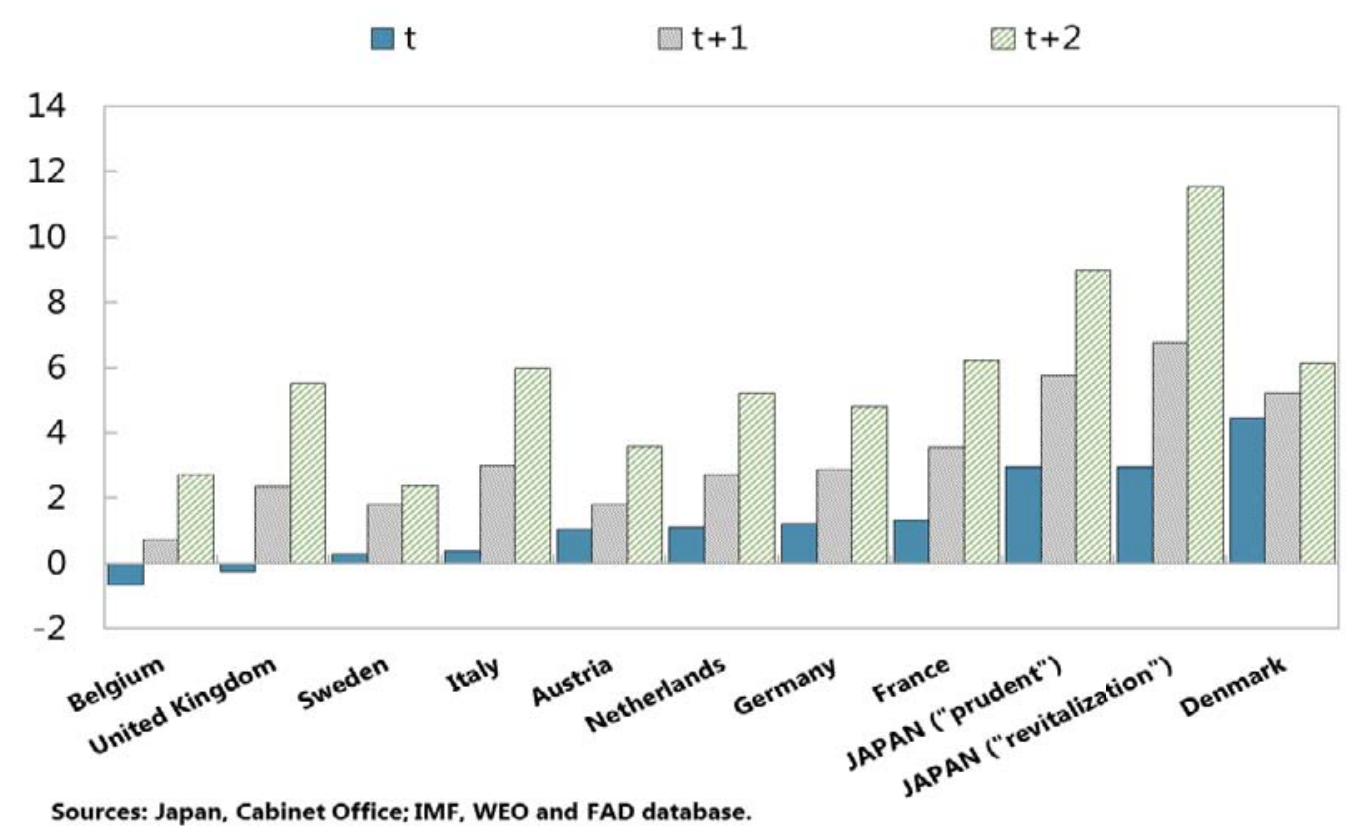

Sources: Japan, Cabinet Office; IMF, WEO and FAD database. Note: Positive value indicates underestimation of debt. 


\section{Opacity and Uncertainty}

Japan's budgetary process highlights major weaknesses in policymaking. For one, the current practice reflects the failure to strike the right balance between the goals of macro stabilization and debt sustainability — as illustrated recently, for instance, by first announcing and then postponing the VAT rate increase. A related implication is that the current approach may distract from considering much-needed reform measures that transcend the choice between an expansionary and a contractionary policy stance and that could help smooth the tradeoff between the competing goals of stabilization and sustainability. ${ }^{21}$

The lack of clearly spelled out priorities and of commitment to a medium-term plan, along with mid-year improvisations through serial enactment of supplementary budgets, build on a long history of deficiencies in Japan's public finances. ${ }^{22}$ More important, such stop-go practices tend to undermine the efficacy of fiscal policy by contributing to policy uncertainty. A multi-pronged effort was launched in 2009 to reform public finances to eliminate government waste and to remove the fog over the budgetary process by introducing mediumterm budgetary planning, program reviews, clear accounting standards, and tax expenditure estimates. The initiative fell short of expectations and was subsequently reversed. ${ }^{23}$ It failed to reduce or eliminate Japan's reputation of opacity in public finances and policymaking. Not surprisingly, Japan stands out as the only major advanced economy missing in a well-known survey of openness in budgetary practices covering more than one hundred countries worldwide. $^{24}$

Absence of transparency in public finances tends to undermine the quality of policymaking, but more important, it creates uncertainty for the private sector. This pattern proceeds in tandem with a monetary policy that is seen as lacking credibility. Thus, neither inflation expectations nor fiscal expectations are anchored, which at least in part may explain the overall reluctance of households and enterprises to consume and to invest, respectively, and the continued stagnation of economic activity. At an extreme, fiscal opacity is known to have a contributed to sovereign debt crises in the past.

Adherence to current budgetary practices does not augur well for the government's ability to cope with mounting challenges in the future. The downside risks of prolonged stagnation in

\footnotetext{
${ }^{21}$ The widely-advocated fiscal stimulus is compared by Tanzi (2013) to prescribing steroids, for symptomatic relief, to a patient suffering from a serious illness. Although used in the context of the Euro debt crisis, the analogy may be equally relevant for Japan.

${ }^{22}$ Wright (2002) characterizes as "smoke and mirrors" the manipulation of the General Account Budget, the Fixed Investment and Loan Program, and multiple Special Accounts, including reliance on creative accounting. Although laced in diplomatic language, in a fiscal transparency ROSC, the IMF (2001) identified some of these practices as well.

${ }^{23}$ See the in-depth analysis in Tanaka (2014a).

${ }^{24}$ See the most recent annual edition of the International Budget Partnership (2015).
} 
the future, coupled with continued rise in public indebtedness, cannot be exaggerated especially with the dramatic contraction of the labor force-predicted to decline by one half between now and the 2080s. The home bias in sovereign bond holdings and extraordinary monetary expansion, with unconventional tools, cannot be counted upon to last indefinitely. ${ }^{25}$

A number of factors in the period ahead suggest a likely erosion of the present life-support system: decline in saving from a rapidly aging population and increasing share of nonRicardian households; pressure on institutional investors to search for higher yield securities; eventual tapering of the monetary expansion; and indefinite stagnation under the heavy weight of further rise in the public debt ratio and population aging. ${ }^{26}$ Such developments suggest that eventually Japan's massive public debt will need to be financed increasingly from the international market, and in the long run increasingly expose Japan to a sudden stop and a debt crisis of extraordinary proportions, with far-reaching repercussions. ${ }^{27}$

Such an outlook begs for a break with past habits of opacity and a determined shift to a fiscal framework characterized by a high level of transparency that would be conducive to a steady progress toward solving Japan's public debt sustainability problem, paving the way to sustained growth. Notably, it was mainly the lack of transparency and mounting public indebtedness that recently motivated the United Kingdom and Italy, among other countries, to adopt recently an IFI, under the assumption that it will improve the government's credibility in the conduct of fiscal policy and help anchor expectations. The case for establishing an IFI is far stronger under the prevailing conditions in, and future prospects for, Japan.

\section{INTERNATIONAL OVERVIEW}

\section{A. Statutes and Structure}

Apart from coalescing under a common definition and aspiring to meet basic standards of good practice, as stated in the OECD Principles, IFIs are rather heterogeneous in their statutory basis, structure, and functions. However, in advanced economies, they tend to be clustered mostly around a few types (Table 1$).{ }^{28}$

\footnotetext{
${ }^{25}$ Arslanalp and Botman (2015) present scenarios on the limits to quantitative easing, given the likely portfolio rebalancing by Japanese banks and institutional investors.

${ }^{26}$ See Reinhart and Rogoff (2009) and Cecchetti and others (2011) on evidence of the growth-constraining effect of high public indebtedness.

${ }^{27}$ In pondering over persistent US budget deficits, Schultze (1989) queried whether it is a big problem to be solved immediately, like in the case of a wolf at the door, or no problem at all as with a cuddly, harmless pussycat, or a languishing problem of termites in the basement, which over time can bring the house down. The implication was that the latter best describes the US case. For Japan, the metaphor is even more appropriate.

${ }^{28}$ IFIs of OECD countries that do not meet minimum standards under the Principles are excluded the international comparison in this section. See, for example, Kopits (2013b) for an assessment of the Germany's
} 
In most countries, the enabling statute of the IFI is set in a law, which in some cases takes the form of a higher-grade organic or constitutional law. In a few countries, presumably because of historical circumstances, the IFI has been established by executive decree. By institutional affiliation, IFIs are distributed more or less evenly between the legislative and the executive branches, if at all. As an exception, in one case (France), the IFI is under the court of audit, which in turn, is related to the judiciary branch. ${ }^{29}$ An additional critical feature in federal systems is that the coverage of the IFI mandate extends to surveillance of subnational government finances. ${ }^{30}$

Table 1. Advanced Economies: Statutes and Structure of Independent Fiscal Institutions

\begin{tabular}{|c|c|c|c|c|c|c|c|c|c|}
\hline & \multirow[t]{2}{*}{ Effective date } & \multirow[t]{2}{*}{ Statute } & \multirow[t]{2}{*}{ Affiliation } & \multirow{2}{*}{$\begin{array}{c}\text { Subnational } \\
\text { coverage }\end{array}$} & \multirow[t]{2}{*}{ Leadership } & \multicolumn{3}{|c|}{ Staff } & \multirow{2}{*}{$\begin{array}{l}\text { Outside } \\
\text { support }\end{array}$} \\
\hline & & & & & & $<10$ & 10 to 50 & $>\mathbf{5 0}$ & \\
\hline United States (CBO) & 1975 & law & legislature & & individual & & & $\mathbf{X}$ & \\
\hline Netherlands (CPB) & 1986 & law & executive & & individual & & & $\mathbf{X}$ & \\
\hline Belgium (HCF) & 1989 & decree & executive & $\mathbf{X}$ & collective (24) & $\mathbf{X}$ & & & $\mathbf{x}$ \\
\hline Korea (NABO) & 2003 & law & legislature & & individual & & & $\mathbf{X}$ & \\
\hline Sweden (FC) & 2007 & decree & executive & & collective (5) & $\mathbf{X}$ & & & $\mathbf{X}$ \\
\hline Canada (PBO) & 2008 & law & legislature & & individual & & $\mathbf{X}$ & & \\
\hline United Kingdom (OBR) & 2010 & law & executive & & collective (3) & & $\mathbf{X}$ & & $\mathbf{X}$ \\
\hline Australia (PBO) & 2011 & law & legislature & & individual & & $\mathbf{X}$ & & \\
\hline Ireland (IFAC) & 2011 & law & none & & collective (5) & $\mathbf{X}$ & & & \\
\hline Portugal (CFP) & 2011 & law & none & $\mathbf{X}$ & collective (5) & & $\mathbf{X}$ & & \\
\hline Slovakia (CBR) & 2012 & constitution & none & & collective (3) & & $\mathbf{X}$ & & \\
\hline Finland (FPAO) & 2013 & law & legislature & & individual & $\mathbf{X}$ & & & \\
\hline France (HCFP) & 2013 & law & judiciary & $\mathbf{X}$ & collective (10) & $\mathbf{X}$ & & & \\
\hline Italy (UPB) & 2014 & constitution & legislature & & collective (3) & & $\mathbf{X}$ & & \\
\hline Spain (AIREF) & 2014 & law & none & $\mathbf{X}$ & individual & & $\mathbf{X}$ & & \\
\hline
\end{tabular}

Sources: Kopits (2013a) and update from IFI webpages.

In principle, neither the statutory form nor the affiliation matters for the actual authority or the independence of the institution. In practice, what matters is not the de jure but the de facto status of the IFI. Nonetheless, a higher-grade law ensures greater permanence and protection because of a broader multiparty consensus behind the establishment of the IFI. As noted, IFIs are fragile institutions; hence, an IFI adopted by simple majority or decree may be

Advisory Council. For the Netherlands and Belgium, the IFIs were legally established in 1945 and 1936, respectively, but without a specific remit in fiscal policy until the effective dates shown in the comparative tables below.

${ }^{29}$ Although formally not part of the judiciary, the court of audit is a quasi-judicial body whose decisions, including sanctions, can be appealed in principle all the way to the highest level of the judiciary branch.

${ }^{30}$ In Belgium and Spain, the need to contain the autonomy of subnational governments seems to have been a major reason for creating the IFI. 
easier to reverse or abolish with a similar action by a successor parliament or government, than an IFI enshrined in the constitution. All else being equal, absence of a formal link to any other public institution should provide greater autonomy to the IFI.

Organizational structure of IFIs varies significantly across countries. Approximately one half of IFIs are endowed with a monocratic authority, while the other half (mostly in Europe) operate under the collective leadership of a council. In most cases the head and members of the IFI are appointed or elected by the legislature, in others they are selected and appointed by the executive, for a fixed, often non-renewable, term. Only in a few countries can the executive dismiss the head of the IFI without cause and/or without the consent of the legislature, a practice that undermines the independence of the institution. Typically, expertise in macro-fiscal and budgetary matters is a prerequisite to lead an IFI.

By and large, there are advantages and disadvantages associated with practically any model. The monocratic model can ensure a higher degree of non-partisanship to the extent the IFI head is under stricter public scrutiny than a collective IFI where the members either subtly, or not so subtly, may represent different political parties or interest groups, thereby diluting the evaluation of the budget bill or of some policy proposal. On the other hand, collective leadership of non-affiliated experts can reduce groupthink, especially if the council includes some council members from abroad - as in Ireland, Portugal, or Sweden. ${ }^{31}$ In either case, The IFI head or council members should serve in a staggered fashion for a term that overlaps with the electoral cycle and is renewable at most only once, to prevent acquiescence to the political authority. The leadership of the institution should be accountable to the legislature and subject to oversight by the audit office, as any other public institution, but immune from dismissal without cause by the political authority.

The size and composition of the IFI staff differs across countries, though in the overwhelming majority, it does not exceed 50 professionals and support personnel. Professional staff is comprised of economists, budget specialists, lawyers, and accountants. Determinants of size are the remit of the institution and the extent of outside support. IFIs entrusted with a large number of tasks tend to be larger; in particular, those that are responsible for real-time costing of specific policy proposals are the largest, given the labor intensity of the function and concentration of this activity at the time the budget bill or proposed amendments are submitted to the legislature. Small size in some countries reflects the fact that a number of oversight functions are being performed by other independent agencies or institutions in close coordination with the IFI. ${ }^{32}$

\footnotetext{
${ }^{31}$ In Portugal, the law prescribes that two out of five council members be non-Portuguese European nationals.

32 In Sweden, the National Institute of Economic Research and the National Financial Management Authority are responsible for preparing short- and medium-term macro-fiscal forecasts; see Calmfors (2013).
} 


\section{B. Remit}

The terms of reference of most IFIs include the preparation of estimates and forecasts of the fiscal and macroeconomic consequences of the budget bill and various proposed fiscal measures in time for consideration by the legislature (in the budget or finance committee and then on the floor) before enactment. Detailed estimation of the budgetary cost of each major proposed expenditure or tax measure is undertaken by only handful of IFIs (Table 2).

In a number of countries, prior to submission of the budget bill, the IFI prepares short- and medium-term no-policy-change projections to serve as the baseline to judge the realism of the government's projections that incorporate the proposed policy measures. Such baseline forecasts are critical for an objective evaluation of the effects of proposed measures (or proposed adjustment) on economic activity and on the budget, which the government may want to exaggerate for the benefit its own political agenda.

In addition, periodically, the IFI prepares quantitative long-term scenarios and sensitivity analyses for specific policy options, with clearly spelled out macroeconomic and demographic assumptions. Some IFIs are developing and incorporating stochastic techniques to assess risks around medium- to long-term fiscal projections, stemming from various sources, including the accumulation of contingent liabilities.

Table 2. Advanced Economies: Functions of Independent Fiscal Institutions

\begin{tabular}{|c|c|c|c|c|c|c|c|c|c|}
\hline & \multirow[t]{2}{*}{ Effective date } & \multicolumn{2}{|c|}{ Macro-fiscal projections } & \multirow{2}{*}{$\begin{array}{c}\text { Macro-fiscal } \\
\text { analysis }\end{array}$} & \multirow{2}{*}{$\begin{array}{c}\text { Policy } \\
\text { costings }\end{array}$} & \multirow{2}{*}{$\begin{array}{c}\text { Fiscal } \\
\text { sustainability } \\
\text { analysis }\end{array}$} & \multirow{2}{*}{$\begin{array}{l}\text { Compliance } \\
\text { with rules or } \\
\text { targets }\end{array}$} & \multirow{2}{*}{$\begin{array}{c}\text { Advisory } \\
\text { role }\end{array}$} & \multirow{2}{*}{$\begin{array}{r}\text { Election } \\
\text { platforms }\end{array}$} \\
\hline & & Monitoring & Preparation & & & & & & \\
\hline United States (CBO) & 1975 & $\mathbf{x}$ & & $\mathbf{x}$ & $\mathbf{x}$ & $\mathbf{x}$ & & & \\
\hline Netherlands (CPB) & 1986 & & $\mathbf{X}$ & $\mathbf{x}$ & $\mathbf{x}$ & $\mathbf{X}$ & $\mathbf{X}$ & & $\mathbf{X}$ \\
\hline Belgium (HCF) & 1989 & $\mathbf{X}$ & & & & $\mathbf{x}$ & $\mathbf{X}$ & $\mathbf{x}$ & \\
\hline Korea (NABO) & 2003 & $\mathbf{x}$ & & & $\mathbf{X}$ & $\mathbf{X}$ & & & \\
\hline Sweden (FC) & 2007 & $\mathbf{X}$ & & $\mathbf{x}$ & & $\mathbf{X}$ & $\mathbf{X}$ & $\mathbf{X}$ & \\
\hline Canada (PBO) & 2008 & $\mathbf{x}$ & & & $\mathbf{x}$ & $\mathbf{x}$ & & & \\
\hline United Kingdom (OBF & 2010 & & $\mathbf{X}$ & & $\mathbf{x}$ & $\mathbf{x}$ & $\mathbf{X}$ & & \\
\hline Australia (PBO) & 2011 & & & $\mathbf{X}$ & $\mathbf{X}$ & $\mathbf{X}$ & & & $\mathbf{X}$ \\
\hline Ireland (IFAC) & 2011 & $\mathbf{X}$ & & & & & $\mathbf{X}$ & $\mathbf{X}$ & \\
\hline Portugal (CFP) & 2011 & $\mathbf{X}$ & & $\mathbf{x}$ & & $\mathbf{x}$ & $\mathbf{X}$ & & \\
\hline Slovakia (CBR) & 2012 & $\mathbf{x}$ & & & $\mathbf{X}$ & $\mathbf{X}$ & $\mathbf{X}$ & & \\
\hline Finland (FPAO) & 2013 & $\mathbf{X}$ & & $\mathbf{x}$ & & $\mathbf{X}$ & $\mathbf{X}$ & & \\
\hline France (HCF) & 2013 & $\mathbf{X}$ & & & & & $\mathbf{X}$ & & \\
\hline Italy (UPB) & 2014 & $\mathbf{X}$ & & $\mathbf{x}$ & & $\mathbf{X}$ & $\mathbf{X}$ & & \\
\hline Spain (AIREF) & 2014 & $\mathbf{x}$ & & $\mathbf{x}$ & & $\mathbf{X}$ & $\mathbf{x}$ & $\mathbf{X}$ & \\
\hline
\end{tabular}

Sources: Kopits (2013a) and update from IFI webpages. 
IFI projections are not necessarily more accurate than other official or private forecasts but, unlike the latter, they disclose publicly all underlying data and methodology. The goal is to assess in real time the reliability of the government's estimates and forecasts, including the associated assumptions, with a view to determining the sustainability of sovereign debt and gauging the risks associated with the prospects.

Notably, in a few countries (Netherlands, UK), where in the past the government's projections had lost credibility owing to a persistent optimistic bias, the IFI is assigned the responsibility of preparing the official macro-fiscal projections for the forthcoming budget, as well as for the medium term. In many countries, IFI surveillance extends beyond evaluating the realism of the government's projections; the institution also conducts macrofiscal analysis in such issues as the overall fiscal stance, the structural balance, and the consistency of envisaged policy proposals.

As part of the surveillance function, most IFIs undertake periodic assessments of public debt sustainability through long-term quantitative scenarios; also, a few IFIs are taking steps toward ascertaining the country's exposure to a range of fiscal risks stemming from potential external shocks as well as contingent liabilities that have proliferated in recent decades. In countries where governments are subject to fiscal rules, ${ }^{33}$ especially in the form of limits on the government deficit and debt under the EU Stability and Growth Pact, the IFI has the added mandate of monitoring compliance with such rules.

Legally, in most countries, all public entities are obliged to provide unlimited access to timely and comprehensive information that are necessary for the IFI to discharge its multiple monitoring function. In some countries, such access needs to be enforced under bilateral memoranda of understanding between the IFI and each government agency or ministry.

In two countries (Australia, Netherlands), on a voluntary basis, political parties are entitled to approach the IFI for an evaluation of the consistency and coherence of the fiscal content of the party's platform in the run-up to an election. ${ }^{34}$ Whereas initially only a few parties had made such a request, by now practically all parties do so, imposing considerable burden on the IFI's work schedule during electoral campaigns.

Exceptionally, in a few countries, IFIs have a normative function. They are called upon to provide fiscal policy advice to the government (Ireland, Sweden) or to recommend budgetary targets (Belgium), but at the risk of appearing to forsake non-partisanship. Even though there is a clear rationale for such a function to be exercised in real time by an independent group of

\footnotetext{
${ }^{33}$ Under the US Budget Enforcement Act of 1990, each legislative bill involving a mandatory expenditure or tax measure was subject to the pay-go rule. This required that the estimated cost of the proposed measure be compensated by equivalent savings from a specified compensatory expenditure cut or tax increase. On the successful experience of compliance with the rule, monitored by CBO, see Reischauer (1993).

${ }^{34}$ On the Dutch experience, see Bos and Teulings (2013).
} 
experts, the IFI exposes itself to accusations of partisanship with potential damage to its reputation. Hence, even if responding to specific requests from legislators or the media, these IFIs tend to be rather circumspect in uttering policy recommendations, strictly supported by evidence and technical analysis. ${ }^{35}$ However, nowhere is the IFI endowed with policymaking authority, and by implication, it cannot have legally binding enforcement power. In other words, the government and the legislature can ignore any diagnosis or evaluation carried out by the IFI.

\section{DESIGN OPTIONS FOR JAPAN}

On the basis of Section II, a strong case can be made for creating an IFI to help correct the prevailing critical weaknesses in Japan's fiscal policymaking. Contrary to the view that Japan already has IFIs, embodied in the Prime Minister's Council on Economic and Fiscal Policy and the Finance Ministry's Fiscal System Council, neither of these institutions meets any attributes enumerated in the OECD Principles. Instead, the Councils perform a useful advisory and analytical role, much like similar official bodies around the world. ${ }^{36}$ For example, the President's Council of Economic Advisors in the United States and the Conseil d'Analyse Economique in France provide policy analysis and advice within the executive branch.

In light of the survey of IFIs in advanced economies, in Section III, there are a number of options which can be considered for the architecture of an IFI for Japan. Drawing on the experience of IFIs with a successful track record and taking into account its own needs, Japan can select from among a number of good practices as regards of the functions, statutes and structure of a prospective IFI. Ideally, the IFI should be a key component of a new fiscal policy framework.

Therefore, the functions of the IFI would primarily be aimed at ensuring the transparency of fiscal policymaking and its effects on the budgetary and macroeconomic outcome, and thus help anchoring expectations. For starters, the IFI would encourage the government to set targets for the general government balance and expenditures, along with major envisaged structural reform measures, over a medium-term horizon. As part of this approach, the government would refrain from resorting to enactment of within-year supplementary budgets, except when warranted by extraordinary unanticipated events beyond its control.

In this context, the IFI would prepare a medium-term macro-fiscal baseline (no policy change) projection that would serve as the backdrop for evaluating the realism of (i) the government's projection that incorporates the envisaged policy measures and (ii) the annual budget bill and its consistency with the target. Estimates of the output gap would allow real-

\footnotetext{
${ }^{35}$ Partly for this reason, in Australia, policy costings by the Parliamentary Budget Office are provided to legislators on a confidential basis.

${ }^{36}$ The political role and influence of the Council on Economic and Fiscal Policy depends largely on the Prime Minister who chairs it ex officio.
} 
time (iv) estimates of the structural (or cyclically adjusted) budget balance and (v) assessment of the fiscal policy stance.

Over time, the IFI would be entrusted with the preparation on a regular basis (possibly annually) of long-term quantitative baseline scenarios to assess public debt sustainability, given Japan's large adjustment needs over a long time horizon especially in light of a rapidly aging population. Besides relying on a baseline scenario, fiscal sustainability analysis should possibly be complemented with a risk assessment applying sophisticated techniques. ${ }^{37}$ As suggested by the recent experience of the UK and New Zealand, the development of the latter entails a non-negligible effort.

At a later stage, responsibility for preparing the official medium-term macro-fiscal projections would be shifted from the government to the IFI, to guarantee impartiality as well as greater time consistency. Also, consideration could be given to deepening the evaluation function by costing each proposed mandatory expenditure or tax measure. As this is the most resource-intensive function, it should await the availability of sufficient manpower to activate it in full. A far less expensive alternative consists of simply requesting the government to conduct costing, which in turn is to be evaluated by the IFI - as done in the UK. Although deemed very useful, evaluation of electoral economic platforms, if solicited by political parties, should be considered much later, given the availability of sufficient resources for the task at hand.

Normative functions should be permanently excluded from the role of the IFI. It must be emphasized that the IFI is not a decision-making body under any circumstances. Equally, an advisory function should be eschewed, given the risk of being publicly regarded as being a political ally of the government in power, which, in turn, could shift blame for a policy decision onto the IFI. This is a powerful reason why usually the remit of IFIs excludes such a function.

As regards the statutory basis, the IFI should be created through an informed and open debate, and enshrined in legislation reached on the basis of a broad political consensus. The institution should not be established simply through a government decree or legislated along party lines, in order to bestow on it the status it deserves and to assert its nonpartisanship. A strong statutory basis can serve as signaling a regime shift toward improved and transparent fiscal governance. Formal affiliation of the IFI to the government, much like an advisory function, carries the risk of government capture. Far less risky would be affiliation to the Diet, or possibly no affiliation at all. In either case, the enabling law should ensure de facto independence for the IFI. Furthermore, to enhance its effectiveness, the IFI should be

\footnotetext{
${ }^{37}$ See the roadmap for a comprehensive risk-adjusted fiscal sustainability analysis provided by Kopits, Ferrarini, and Ramayandi (2016).
} 
charged with oversight beyond the central government and its agencies, that is, with jurisdiction over subnational governments and the rest of the public sector.

In terms of structure, the IFI can consist of an individual or a collective leadership, but its assessments and projections should be based on impartial expert opinion. A technically competent and eloquent individual head tends to ensure that, under the spotlight, the IFI's evaluations and projections are more likely to be based on expert opinion. However, a collective leadership of non-affiliated experts could be inclined to render a balanced opinion and reduce groupthink. The IFI's work, if limited to the above envisaged functions, could be performed by a lean staff of some 50 professionals, comprised mainly of economists and budget specialists, and including administrative and other support staff. Eventually, as the coverage of the IFI's was to be extended to the entire public sector and to include policy costing, staff size would need to be increased commensurately.

\section{Summary AND CONCLUSION}

In response to the recent financial crisis and the ensuing buildup in public indebtedness, there has been a surge of interest in creating independent fiscal institutions (IFIs) with a view to improving the quality of public finances, and to strengthening the credibility of government policy. By now, well over a dozen advanced economies have adopted an IFI in line with the OECD Principles for Independent Fiscal Institutions, which codifies internationally accepted good practices. IFIs do not have a normative role; they are not intended to act as decisionmaking or advisory bodies. IFIs are typically charged with only a diagnostic remit, namely, to evaluate in real time fiscal policy and its budgetary and macroeconomic consequences, and to assess debt sustainability and risk.

Over the years, there has been a growing and widespread critical perception - both at home and abroad — of Japan's fiscal policymaking on several counts, but mostly for the absence of transparency and predictability. As a result, government initiatives and programs are faced with a sharp erosion of credibility, while fiscal expectations remain unanchored. But, more important, the upshot is that fiscal policy has been impotent either in stimulating economic activity or in restoring public debt sustainability. Continuation of current trends in fiscal behavior is likely to lead over time to an ever higher public debt-to-GDP ratio, driven by the rapidly shrinking population and the two-way loop between the debt ratio and economic growth. The outlook is further aggravated by the likely decline in the home bias of Japanese households and financial institutions to holding government securities, and by the eventual rise in interest rates upon withdrawal of the extraordinary monetary expansion currently under way.

In all, a strong case can be made for establishing an IFI to help correct critical weaknesses in Japan's fiscal policymaking. An IFI cannot, of course, remedy all current failings of policymaking, but it can certainly contribute to a major improvement, especially if it is introduced as part of a broader reform of the fiscal framework that would incorporate a 
medium-term perspective and abandonment of the rather fitful and improvised short-run approach - exemplified by the routine practice of mid-year supplementary budgets, adopted as a result of the opaque dynamics of policy formulation - that characterizes Japan's current fiscal system.

There are a number of options which need to be considered for the architecture of an IFI for Japan, drawing on the successful experience of IFIs with a sufficiently long track record. Major functions of the IFI would include: preparation of Japan's official short- and mediumterm macro-fiscal forecasts, to correct for the present lack of credible forecasts; analysis of the government's fiscal policy stance, reflected in the budget bill and other proposed fiscal measures; oversight of compliance with the government's own medium-term fiscal goals; and assessment of public debt sustainability on the basis of long-term quantitative scenarios, possibly adjusted for risk.

The IFI should be created through informed debate and legislation reached on the basis of a broad political consensus; although formally affiliated to the Diet, or with no affiliation at all, the IFI must enjoy de facto independence; and the coverage of its remit may need to be extended beyond the national government, to the rest of the public sector. While there are benefits and drawbacks of different leadership structures, the main objective should be to ensure that the IFI's assessments and projections are based on expert opinion, rather than on a bipartisan opinion; and the IFI's work, if limited to the envisaged functions, could be supported by a relatively small technical staff.

Japan is facing a critical choice between continued adherence to a budget process that over several decades has failed to stimulate the economy or to restore fiscal sustainability, on the one hand, and the other, to undertake a regime shift in policymaking, including the adoption of an IFI to shed clarity and induce efficacy in that process. Given a future outlook of flattened labor productivity, marked population aging, and staggering public sector indebtedness, the stakes for Japan are high. Failure to consider the above options for improving fiscal governance may doom any attempt at anchoring expectations and jumpstart economic activity onto a path of sustained growth. 


\section{References}

Arslanalp, S., and D. Botman (2015) "Portfolio Rebalancing in Japan: Constraints and Implications for Quantitative Easing” IMF Working Paper WP/15/186, August.

Bos, F., and C. Teulings (2013) "Netherlands: Fostering Consensus on Fiscal Policy" in G. Kopits, ed., Restoring Public Debt Sustainability: The Role of Independent Fiscal Institutions, Oxford University Press.

Beetsma, R., and X. Debrun (2016) "Fiscal Councils: Rationale and Effectiveness" IMF Working Paper WP/16/86, April.

Budd, A. (2013) "Preface" in G. Kopits, ed., Restoring Public Debt Sustainability: The Role of Independent Fiscal Institutions, Oxford University Press.

Cecchetti, S. G., M. S. Mohanty, and F. Zampoli (2011) “Achieving Growth Amid Fiscal Imbalances: The Real Effects of Debt" in Achieving Maximum Long-Run Growth, Symposium sponsored by the Federal Reserve Bank of Kansas City.

Debrun, X. and M.S. Kumar (2007) "Fiscal Rules, Fiscal Councils and All That: Commitment Devices, Signalling Tools or Smokescreens?" in Fiscal Policy: Current Issues and Challenges, Banca d'Italia.

Frankel, J.A. (2011) "Over-optimism in Forecasts by Official Budget Agencies and Its Implications," Oxford Review of Economic Policy, vol. 27, no. 4.

Harding, R. (2016) “Abenomics Opponents Pounce on Expected Sales Tax Delay,” Financial Times, May 31, p. 2.

Ihori, T. (2014) "Fiscal Consolidation in the Political Economy in Japan" in T. Ihori and K. Terai, eds., Political Economy of Fiscal Consolidation in Japan, Springer Verlag.

International Budget Partnership (2015) Open Budget Survey 2015, Washington, DC.

International Monetary Fund (2001) "Japan: Report on the Observance of Standards and Codes-Fiscal Transparency Module” IMF Country report No. 01/156, August.

International Monetary Fund (2013) “The Functions and Impact of Fiscal Councils,” July 16.

Joyce, P. (2011) The Congressional Budget Office: Honest Numbers, Power, and Policymaking, Georgetown University Press.

Kopits, G., ed. (2013a) Restoring Public Debt Sustainability: The Role of Independent Fiscal Institutions, Oxford University Press.

Kopits, G. (2013b) “A Minimalist Approach to Fiscal Oversight,” VoxEU, December 24. 
Kopits, G., B. Ferrarini, and A. Ramayandi (2016) "Exploring Risk-Adjusted Fiscal Sustainability Analysis for Asian Economies," ADB Working Paper Series No. 483, May.

Krugman, P. (1998) “It's Baaack: Japan's Slump and the Return of the Liquidity Trap" Brookings Papers on Economic Activity, No. 2.

Leeper, E.M. (2010). "Monetary Science, Fiscal Alchemy" in Macroeconomic Challenges in the Decade Ahead, A Symposium Sponsored by the Federal Reserve Bank of Kansas City, Jackson Hole, Wyoming, August 26-28.

OECD (2013) Principles for Independent Fiscal Institutions, Paris, February 12. http://www.pbodpb.gc.ca/web/default/files/files/files/Revised\%20IFI\%20Principles_EN\%20-\%2013-Feb13.pdf

Puviani, A. (1903) Teoria della Illusione Finanziaria. Palermo, Laterza.

Reinhart, C., and K. Rogoff (2009) This Time is Different: Eight Centuries of Financial Folly, Princeton University Press.

Reischauer, R.D. (1993) "CBO Testimony: Statement before the Subcommittee on Legislation and National Security, Committee on Government Operations, U.S. House of Representatives" Congressional Budget Office, May 13.

Rivlin, A. (2013) "Politics and Independent Analysis" in G. Kopits, ed., Restoring Public Debt Sustainability: The Role of Independent Fiscal Institutions, Oxford University Press.

Schultze, C. (1989) “Of Wolves, Termites, and Pussycats” The Brookings Review, Summer.

Tanaka, H. (2014a) "Economic and Financial Management under the Democratic Party of Japan (DPJ) Administration,” OECD Journal on Budgeting, Vol. 14, No. 1.

Tanaka, H. (2014b) "Policy-Making Process and Relationships between Politicians and Bureaucrats in Japan," Meiji Journal of Governance Studies, Vol. 2.

Tanzi, V. (2013) Dollar, Euros and Debt: How We Got into the Fiscal Crisis and How We Get Out of It, Palgrave Macmillan.

Walker, W.C. (2002) "Ricardian Equivalence and Fiscal Policy Effectiveness in Japan" Asian Economic Journal, Vol. 16, No. 3. 
Werner, R.A. (2004) "Why has Fiscal Policy Disappointed in Japan? Revisiting the PreKeynesian View on the Ineffectiveness of Fiscal Policy” Sophia University, Tokyo, unpublished, January.

Wren-Lewis, S. (2013) "Comparing the Delegation of Monetary and Fiscal Policy" in G. Kopits, ed., Restoring Public Debt Sustainability: The Role of Independent Fiscal Institutions, Oxford University Press.

Wright, M. (2002) Japan's Fiscal Crisis: The Ministry of Finance and the Politics of Public Spending, 1975-2000, Oxford University Press. 